\title{
GLYCATED HAEMOGLOBIN (HBA1C) AND ITS ASSOCIATION WITH ISCHAEMIC STROKE IN DIABETICS AND NON- DIABETICS.
}

KEY WORDS:

\section{Dr Mohan Raj}

\section{Dr. Manu}

Reddy.s*

\section{Dr Kiruthika}

\section{Dr Raghul raju}

Department of General Medicine, Meenakshi medical college and research institute, enathur kancheepuram, chennai.

Department of General Medicine, Meenakshi medical college and research institute, enathur kancheepuram, chennai.*Corresponding Author

Department of General Medicine, Meenakshi medical college and research institute, enathur kancheepuram, chennai.

Department of General Medicine, Meenakshi medical college and research institute, enathur kancheepuram, chennai.

\section{INTRODUCTION}

Stroke is a condition that results in high mortality rates and severe disabilities. Stroke is expected to be the second most important cause of mortality worldwide by 2020. Most stroke survivors can and do experience improvements in their functional abilities, but the amount, rate, timing, pattern, type, and ultimate outcome of the improvements differ across patients and situations. 1 Stroke severity and patient age are the main predictors of stroke outcome in the acute phase 2 . Additional important predictors include functional status prior to stroke, presence of comorbid medical conditions, etiologies and the vascular territories affected. $\underline{3}$

Diabetes mellitus is one of the established risk factors for stroke. It has been demonstrated that diabetic patients had worse residual neurological deficits and functional outcome when compared with nondiabetic patients. 4 Hyperglycemia occurred in up to one-third of patients with acute ischemic stroke and was associated with higher mortalities independent of age and stroke severity [ [5]. However, few studies have assessed the effects of prestroke glycemic control status on clinical outcomes in acute stroke patients. In a study published in 2011 , the association between prestroke glycemic control status and neurological or functional outcomes was evaluated in 3,627 patients with first-ever ischemic stroke. It was suggested that the serum hemoglobin Alc level on admission was a significant independent predictor for clinical outcomes [ 6 ].

Hemoglobin Alc has a direct relationship with mean glycemia because erythrocytes are continuously glycated during their 120-day lifespan, which means that the rate of formation of glycated hemoglobin, also called $\mathrm{HbAlc}$, is proportional to the ambient glucose concentration [7]. In the diabetes control and complication trial, an $\mathrm{HbAlc}$ of $6 \%$ corresponded to a mean serum glucose level of $135 \mathrm{mg} / \mathrm{dL}$, and the measurement of $\mathrm{HbAl} \mathrm{c}$ has been the primary index of glycemia [7]. An HbAlc test can be used to diagnose prediabetes or diabetes and check the long-term control of blood glucose levels in people with diabetes. Serum blood glucose level changes during the day for many reasons, including medicine, diet, exercise, and the level of insulin in the blood, while the $\mathrm{HbAlc}$ test result is not affected by any recent changes [8]. $\mathrm{HbAlc}$ is independent risk factor for diabetic complication, with the risks of macrovascular events, such as cardiovascular death, non-fatal myocardial infarction or non-fatal stroke, and death only clearly lower when down at levels of $7 \%$ [8].

Approximately $30 \%$ to $40 \%$ of acute ischemic stroke patients present with hyperglycemia at admission either as a result of preexisting diabetes mellitus or acute stress response. Type 2 diabetes, a disease that affects more than 220 million people worldwide, has an alarming number of new cases in the Asian population and holds a 2 - to 6 -fold increased risk for ischemic stroke. Moreover, hyperglycemia is associated with poor outcome in acute ischemic stroke. Thus, in recent years, there has been a growing interest in methods to manage hyperglycemia in acute ischemic stroke $[9,10]$.

$\mathrm{HbAlc}$ level is widely recommended as the therapeutic guideline for the prevention of cardiovascular complications in patients with diabetes [11]. Recently published clinical practice recommendations from the American Diabetes Association advocate the use of a $\mathrm{HbAlc}$ level greater than $6.5 \%$ for the diagnosis of diabetes, largely on the basis of the established association between $\mathrm{HbAlc}$ level and microvascular complications. Compared with fasting glucose, $\mathrm{HbAl} \mathrm{c}$ has higher repeatability, can be tested in a non-fasting status, and is a relatively stable marker for glucose level. The disadvantage of the use of $\mathrm{HbAlc}$ in the diagnosis of diabetes might be the fact that the measurement of $\mathrm{HbAlc}$ level is not standardized, which may result in unreliable values in different laboratories and countries [12].

Despite the recent impending increase in risk for diabetes and ischemic stroke in Asians, and the increasing importance of predictive value of $\mathrm{HbAlc}$ in future risk for cardiovascular disease, there are no studies that have investigated the association of ischemic stroke with $\mathrm{HbAlc}$ level in Asians. We cross-sectionally analyzed the risk for ischemic stroke according to $\mathrm{HbAlc}$ level in indian male patients admitted due to acute ischemic stroke without a previous history of diabetes

The socioeconomic prospects of Asia have recently taken a urban localisation. This has brought changes in risk of cardiovascular diseases especially stroke.13,14 Prevalence of diabetes and prediabetes has increased in Asia including India in the past decade, nearly doubling during this era. 15,16,17 Diabetes and prediabetes both show increased risk for ischaemic stroke and are associated with poor patient outcomes.18,19

With the increased risk of diabetes and ischaemic stroke in Asians, the importance of predictive value of glycated haemoglobin ( $\mathrm{HbAlc}$ ) has been an area of active study in recent years. 20,21

\section{AIMS \& OBJECTIVES}

1. The aim of this study was to analyse the role of HbAlc in the risk prediction of ischaemic stroke in Indian population without diabetes.

2. We further studied the difference between $\mathrm{HbAlc}$ values of individuals with and without diabetes with stroke.

\section{MATERIALS AND METHODS} dramatic change including changes in lifestyle, diet and 
This single centre, descriptive, case-control study was carried out on inpatients admitted to department of General Medicine, Meenakshi Medical College, kancheepuram for a period of 4 months from july 2019 to October 2019.All the patients of both genders $\geq 18$ years of age were included in the study.

The study was approved by the institutional ethical committee and carried out in a tertiary care hospital.

\section{INCLUSION CRITERIA}

Acute Ischemic stroke patients

\section{EXCLUSION CRITERIA}

- Intra cerebral haemorrhage

- Space occupying lesions

- Sub arachnoid haemorrhage

- Cerebral venous thrombosis

- Transient ischemic attacks

- Patients with recurrent cerebrovascular events

A semi structured proforma was prepared which included socio demographic details, detailed history, clinical examination and requisite investigations available at meenakshi hospital. History includes all of the symptoms pertaining to the ischemic stroke in detail with emphasis on all the risk factors including the glycemic status at the time of admission.

$\mathrm{HbAlc}$ levels, fasting blood glucose levels, random blood glucose levels, lipid profiles and blood pressure (BP) were recorded for all individuals. HbAlc levels were recorded at the time of stroke when patients were initially admitted. Height and weight were measured and body mass index (BMI) was calculated by dividing the weight $(\mathrm{kg})$ by the height (m2). Smoking history was noted. A total of 100 diabetics and 100 non diabetics were included in the study who fulfilled the inclusion criteria and gave informed consent.

All patients with stroke had suffered from focal symptoms of stroke and were observed within 1 week of symptom onset. The diagnosis of stroke was made by the Medicine consultant on the basis of history revealing focal symptoms, clinical examination supporting it and by neuroimaging ie, CT scan and/or MRI brain. Furthermore, patients with otherwise unclear or suspicious diagnosis of stroke were also not included for analysis. The following laboratory

investigations were performed as a part of routine work up like complete blood counts, liver function tests, renal function tests, electrolytes, ECG, Chest X-ray, fasting blood sugar, random blood sugar,urine routine examination, echocardiography, coagulation profile, $\mathrm{HbAlc}$ and lipid profile. Lipid profile panel consisted of total cholesterol (TC), high- density lipoprotein cholesterol (HDL-C), low-density lipoprotein cholesterol (LDL-C) and triglyceride cholesterol (TGL-C) levels.

Criteria for diagnosis of diabetes mellitus was done following the criteria of American Diabetes Association (ADA, 2011); symptoms of diabetes plus random blood concentration ${ }^{3} 200$ $\mathrm{ml} / \mathrm{dl}$ or fasting plasma glucose $126 \mathrm{ml} / \mathrm{dl}$ or $\mathrm{HbAlc}>6.5 \%$ or two-hour plasma glucose $300 \mathrm{ml} / \mathrm{dl}$ during an oral glucose tolerance test.

The plasma venous glucose level was taken within 24 hours after admission for every patient. Glycosylated haemoglobin (HbAIC) was done to ascertain whether it was stress diabetes or newly diagnosed diabetes. The patient with a raised blood glucose on admission and normal HbAIC level was considered as having stress hyperglycaemia. The patients were divided into 4 groups: euglycaemic patients with no history of diabetes having normal blood glucose and normal
$\mathrm{HbAIC}$ concentration; patients with stress hyperglycaemia (no history of diabetes with normal HbAIC but raised blood sugar at admission); newly diagnosed diabetics (no history of diabetes, HbAIC greater than normal); and lastly, known diabetic patients.

The data was analysed using SPSS V.22.0. Descriptive analysis was carried out and reported as mean \pm SD for continuous variables whereas frequencies and percentages were calculated for categorical variables. A comparison was made between age, gender, BMI, smoking, FBS, HbAlc, HDL-C, LDLC,TGL-C,TC, SBP and DBP values on a subset of patients in two groups; with diabetes versus without diabetes with ischaemic stroke. p Values $<0.05$ were considered statistically significant.

\section{RESULTS}

Out of the 200 patients, 56 cases (28\%) of stroke occurred in the age group of 51 - 60 years; another 60 cases (26\%) occurred in the age group of $61-70$ years (Table I). This shows that the commonest age group is in the age group 50 - 70 years as detected by our study.

Table I: Age-wise distribution of patients.

\begin{tabular}{|l|l|l|l|}
\hline $\begin{array}{l}\text { Age } \\
\text { groups in } \\
\text { years }\end{array}$ & $\begin{array}{l}\text { No. of patients } \\
\text { Diabetics } \\
\mathbf{n}\end{array}$ & $\begin{array}{l}\text { No. of patients } \\
\text { Non Diabetics } \\
\mathbf{n}\end{array}$ & $\begin{array}{l}\text { Total } \\
\mathbf{n}(\%)\end{array}$ \\
\hline Up to 40 & 5 & 3 & $\mathbf{8 ( 4 \% )}$ \\
\hline $41-50$ & 16 & 13 & $\mathbf{2 9 ( 1 4 . 5 \% )}$ \\
\hline $51-60$ & 37 & 19 & $\mathbf{5 6}(\mathbf{2 8 \% )}$ \\
\hline $61-70$ & 35 & 25 & $\mathbf{6 0 ( 3 0 \% )}$ \\
\hline Above 70 & 27 & 20 & $\mathbf{4 7}(\mathbf{2 3 . 5 \% )}$ \\
\hline Total & $\mathbf{1 0 0 ( 5 0 \% )}$ & $\mathbf{1 0 0 ( 5 0 \% )}$ & $\mathbf{2 0 0 ( 1 0 0 \% )}$ \\
\hline
\end{tabular}

There are 63 cases of stroke with euglycaemia, 26 cases of stroke with hyperglycaemia including stress hyperglycaemia, 11 newly detected diabetes, and 100 known diabetes. (Table II).

Table II: Classification of patients according to glycaemic status.

\begin{tabular}{|l|l|l|}
\hline Glycaemic status & No. of cases & Percentage \\
\hline Euglycaemic & 63 & $31.5 \%$ \\
\hline Hyperglycaemic & 26 & $13 \%$ \\
\hline New diabetic & 11 & $5.5 \%$ \\
\hline Known diabetic & 100 & $50 \%$ \\
\hline Total & 200 & $100 \%$ \\
\hline
\end{tabular}

Mean age was $53.75 \pm 1.77$ (Range: $21-82$ ) years in diabetes group and $58.51 \pm 2.11$

(Range: 23 - 86) in without diabetes group. Among the individuals with diabetes, 61 were males while 39 were females. Among individuals without diabetes, there were 54 males and 46 females. Mean age and gender were not statistically significantly different between the two groups. When HbAlc values were compared between individuals with diabetes and individuals without diabetes with stroke, mean $\mathrm{HbAlc}$ values were significantly higher in diabetes group $(7.81 \pm 2.34$ vs $6.23 \pm 2.17)(p<0.05)$ but other parameters were not statistically significantly different ( $>0.05$; Table III).

Table III : Comparison between individuals with diabetes and without diabetes with stroke

\begin{tabular}{|c|c|c|c|}
\hline Variables & $\begin{array}{c}\text { Individuals } \\
\text { without diabetes } \\
\text { (n=100) }\end{array}$ & $\begin{array}{c}\text { Individuals } \\
\text { with diabetes } \\
\text { (n=100) }\end{array}$ & p Value \\
\hline Age (years) & $53.75 \pm 1.77$ & $58.51 \pm 2.11$ & 0.57 \\
\hline $\begin{array}{c}\text { Gender/sex } \\
\text { (males) }\end{array}$ & 61 & 54 & 0.48 \\
\hline $\begin{array}{c}\text { Gender/sex } \\
\text { (females) }\end{array}$ & 39 & 46 & \\
\hline \multicolumn{4}{|r|}{} \\
\hline
\end{tabular}




\begin{tabular}{|c|c|c|c|}
\hline FBS (mg/dL) & $118.61 \pm 6.45$ & $132.71 \pm 5.17$ & 0.34 \\
\hline HbAlc (\%) & $6.23 \pm 2.17$ & $7.81 \pm 2.34$ & $<0.01$ \\
\hline HDL-C (mg/dL) & $46.93 \pm 2.29$ & $44.92 \pm 5.67$ & 0.67 \\
\hline LDL-C (mg/dL) & $97.13 \pm 6.61$ & $99.43 \pm 8.50$ & 0.93 \\
\hline TGL-C (mg/dL) & $163.43 \pm 31.24$ & $185.12 \pm 24.56$ & 0.55 \\
\hline TC (mg/dL) & $164.50 \pm 24.60$ & $177.65 \pm 25.21$ & 0.35 \\
\hline SBP (mm Hg) & $162.01 \pm 52.21$ & $173.55 \pm 17.99$ & 0.13 \\
\hline DBP (mm Hg) & $89.12 \pm 18.16$ & $94.17 \pm 8.41$ & 0.16 \\
\hline BMI (kg/m2) & $24.19 \pm 2.14$ & $26.12 \pm 3.45$ & 0.32 \\
\hline
\end{tabular}

Funding: No funding sources

Conflict of interest: None declared

Comparison between individuals with diabetes and without diabetes with stroke: values are presented as mean \pm SD.

BMI, body mass index; BSF, blood sugar fasting; DBP, diastolic blood pressure; HbAlc, glycated haemoglobin; HDL-C, highdensity lipoprotein cholesterol; LDL-C, low-density lipoprotein cholesterol; SBP, systolic blood pressure; TC, total cholesterol;TGL-C, triglyceride

Cholesterol

\section{DISCUSSION}

Diabetes mellitus is a metabolic disease prevalent throughout the world and its burden has been increasing in developing and underdeveloped countries. The diversity of this disease varies greatly throughout the world in respect to cut-off values, prevalence and associations.

Prediabetes is an independent risk factor for stroke but most patients with acute stroke are not aware of whether or not they are prediabetic. HbAlc determination is currently accepted for prediabetes diagnoses.

$\mathrm{HbAlc}$ level is an indicator of mean glucose control in the previous $60-90$ days in patients with or without diabetes mellitus. HbAlc level is a good diagnostic tool but is also helpful for prognosis and to monitor therapeutic effects of drugs in diabetes. Well controlled and steady blood glucose levels can help prevent cardiovascular complications in patients with diabetes mellitus.22

Current study showed that patients with ischaemic stroke had significantly higher mean $\mathrm{HbAlc}$ level $(7.81 \pm 2.34$ vs $6.23 \pm 2.17)(p<0.05)$ between Diabetics and Non diabetics.

Myint et al carried out a study on a population of more than 10 000 patients and found that 164 incident strokes after adjustment for confounding variables (age, sex and cardiovascular risk factors), the relative risks for stroke with $\mathrm{HbAlc}$ concentrations $5-5.4 \%, 5.5-6.9 \%$ and $\geq 7 \%$ were 0.7 , 0.8 and 2.8 , respectively, compared with those with $\mathrm{HbAlc}$ $<5 \%{ }^{23}$

A Mexican study concluded that diabetes and prediabetes are highly prevalent in hospitalised patients with ischaemic stroke. They suggested introducing the routine screening for diabetes and prediabetes via $\mathrm{HbAlc}$ testing in all patients with ischaemic stroke. ${ }^{24}$

\section{Limitation}

The limitation was that the diagnosis of diabetes was based on history, previous health records, levels of fasting glucose and $\mathrm{HbAl} \mathrm{c}$ but glucose challenge test was not performed as a part of this study. Although recent guidelines recommend that fasting glucose and $\mathrm{HbAlc}$ levels are sufficient to diagnose diabetes, there is still a possibility that individuals with diabetes could have been missed.

\section{CONCLUSION}

Severity of stroke correlates with the glycaemic status of the patients in diabetics and non-diabetics. Hyperglycaemia, an important risk factor in non-diabetic patients after acute stroke is a stress response reflecting more severe neurological damage. Management of hyperglycaemia in patients with diabetes and non-diabetes is an important aspect of the emergency management of stroke.

\section{REFERENCES}

1) Khan MI,Weinstock RS. Chapter 16: Carbohydrates. In: McPherson RA, Pincus MR, editors. Henry's Clinical Diagnosis and Management by Laboratory Methods.22nd ed.Philadelphia, PA:Saunders Elsevier;2011.pp.210-25.

2. World Health Organization (WHO) Use of Glycated Haemoglobin ( $\mathrm{HbAlc}$ ) in the Diagnosis of Diabetes Mellitus Abbreviated Report of a WHO Consultation. Geneva:WHO;2011. [Google Scholar].

3. Frankel MR, Morgenstern LB, Kwiatkowski T, Lu M,Tilley BC, Broderick JP, et al. Predicting prognosis after stroke: a placebo group analysis from the National Institute of Neurological Disorders and Stroke rt-PA Stroke Trial. Neurology. 2000;55:952-959.

4. Muir KW, Weir CJ, Murray GD, Povey C, Lees KR. Comparison of neurological scales and scoring systems for acute stroke prognosis. Stroke. 1996;27:1817-1820.

5. Andersen KK, Andersen ZJ, Olsen TS. Predictors of early and late case-fatality in a nationwide Danish study of 26,818 patients with first-ever ischemic stroke.Stroke. 2011;42:2806-2812.

6. Knoflach M, Matosevic B, Rucker M, Furtner M, Mair A, Wille G, et al. Functional recovery after ischemic stroke: a matter of age: data from the Austrian Stroke Unit Registry. Neurology. 2012;78:279-285.

7. Petty GW, Brown RD, Jr, Whisnant JP, Sicks JD, O'Fallon WM, Wiebers DO. Ischemic stroke subtypes : a population-based study of functional outcome, survival, and recurrence. Stroke.2000;31:1062-1068.

8. Nedeltchev K, der Maur TA, Georgiadis D, Arnold M, Caso V, Mattle HP, et al. Ischaemic stroke in young adults: predictors of outcome and recurrence. J Neurol Neurosurg Psychiatry. 2005;76:191-195.

9. Ergul A, Li W, Elgebaly MM, Bruno A, Fagan SC. Hyperglyce $\neg$ mia, diabetes and stroke:focus on the cerebrovasculature.Vas $\urcorner$ cul Pharmacol 2009;51:44-9.

10. Ramachandran A, Ma RC, Snehalatha C. Diabetes in Asia. Lancet 2010;375:408-18.

11. TaharaY, Shima K. Kinetics of $\mathrm{HbAl}$ lc, glycated albumin, and fructosamine and analysis of their weight functions against preceding plasma glucose level. Diabetes Care 1995;18:440-7.

12. American Diabetes Association. Diagnosis and classification of diabetes mellitus. Diabetes Care 201 1;34 Suppl 1:S62-9.

13. Burke TA, Venketasubramanian RN. The epidemiology of stroke in the East Asian region: a literature-based review. Int J Stroke 2006;1:208-15.

14. Nomani AZ, Nabi S, Ahmed S, et al. High HbAlc is associated with higher risk of ischaemic stroke in Pakistani population without diabetes. Stroke and Vascular Neurology 2016;1:e000018. doi:10.1136/svn-2016-000018.

15. Qureshi MS, Iqbal M, Nomani AZ. Rapidly increasing prevalence and associations of diabetes mellitus in a rural community of Pakistan. J Diabetol 2014;3:3.http://www.journalofdiabetology.org

16. American Diabetes Association. Diagnosis and classification of diabetes mellitus.Diabetes Care 201 1;34(Suppl 1):S62-9.

17. de Vegt F, Dekker JM, Ruhé HG, et al. Hyperglycaemia isassociated with allcause and cardiovascular mortality in the Hoorn population: the Hoorn Study. Diabetologia 1999;42:926-3.

18. Selvin E, Coresh J, Shahar E, et al. Glycaemia (haemoglobin Alc) and incident ischaemic stroke: the Atherosclerosis Risk in Communities (ARIC) Study. Lancet Neurol 2005;4:82 1-6.

19. Hu GC, Hsieh SF, Chen YM, et al. Relationship of initial glucose level and allcause death in patients with ischaemic stroke: the roles of diabetes mellitus and glycated hemoglobin level. Eur J Neurol 2012;19:884-91.

20. Pradhan AD, Rifai N, Buring JE, et al. Hemoglobin Alc predicts diabetes but not cardiovascular disease in nondiabetic women. Am J Med 2007;120:720-7.

21. Park S, Barrett-Connor E, Wingard DL, et al. GHb is a better predictor of cardiovascular disease than fasting or postchallenge plasma glucose in women without diabetes. The Rancho Bernardo Study. Diabetes Care 1996;19:450-6.

22. American Diabetes Association. Diagnosis and classification ofdiabetes mellitus.Diabetes Care 2011;34(Suppl 1):S62-9.

23. Myint PK, Sinha S, Wareham NJ, et al. Glycated hemoglobin and risk of stroke in people without known diabetes in the European Prospective Investigation into Cancer (EPIC)-Norfolk prospective population study: a threshold relationship? Stroke 2007;38:271-5.

24. Huisa BN, Roy G, Kawano J, et al. Glycosylated hemoglobin for diagnosis of pre-diabetes in acute ischemic stroke patients. J Stroke Cerebrovasc Dis 2013;22:e564-7. 